\title{
The diagnosis of insulitis in human type 1 diabetes
}

\author{
M. L. Campbell-Thompson • M. A. Atkinson - A. E. Butler • N. M. Chapman • \\ G. Frisk • R. Gianani • B. N. Giepmans • M. G. von Herrath • H. Hyöty • \\ T. W. Kay • O. Korsgren • N. G. Morgan • A. C. Powers • A. Pugliese • \\ S. J. Richardson • P. A. Rowe • S. Tracy • P. A. In't Veld
}

Received: 11 June 2013 / Accepted: 5 August 2013 /Published online: 5 September 2013

(C) Springer-Verlag Berlin Heidelberg 2013

To the Editor: During a workshop concerning the histopathological characteristics of insulitis in human type 1 diabetes (fifth annual meeting of the JDRF Network for Pancreatic Organ Donors with Diabetes [nPOD], 10 February 2013,

M. L. Campbell-Thompson • M. A. Atkinson • P. A. Rowe Department of Pathology, Immunology, and Laboratory Medicine, University of Florida, Gainesville, FL, USA

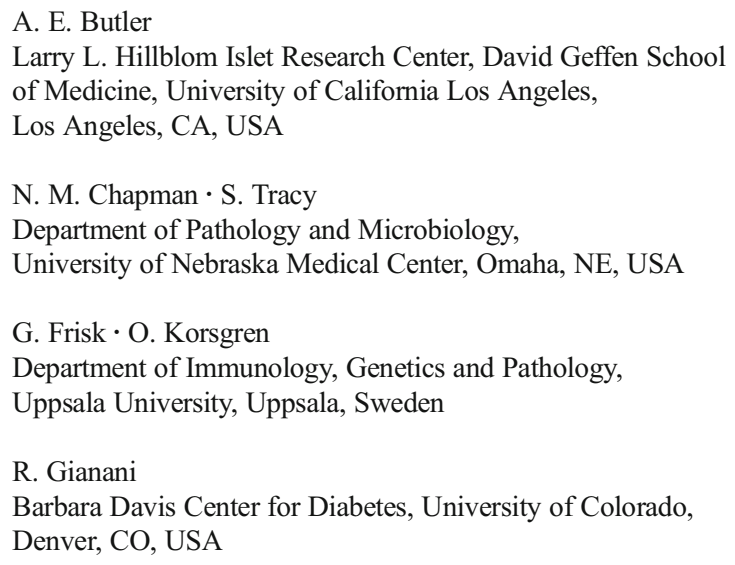

Jacksonville, FL, USA), a consensus opinion was reached on the criteria necessary for the diagnosis of insulitis, and a definition of insulitis was agreed, as detailed in the text box. Workshop attendees included many leading researchers in the
M. G. von Herrath

Type 1 Diabetes Center, La Jolla Institute for Allergy and Immunology, La Jolla, CA, USA

H. Hyöty

Department of Virology, University of Tampere and Fimlab Laboratories, Pirkanmaa Hospital District, Tampere, Finland

T. W. Kay

St Vincent's Institute of Medical Research, Fitzroy, VIC, Australia

N. G. Morgan · S. J. Richardson

University of Exeter Medical School, Exeter, UK

A. C. Powers

Vanderbilt University Medical Center, Nashville, TN, USA

A. Pugliese

Miller School of Medicine, University of Miami, Miami, FL, USA

\section{P. A. In't Veld $(\square)$}

Department of Pathology, Diabetes Research Center, Vrije

Universiteit Brussel, Laarbeeklaan 103, B1090 Brussels, Belgium

e-mail: intveld@vub.ac.be 
field of beta cell biology and the pathology of human type 1 diabetes.

\section{Consensus definition of insulitis}

Patients with insulitis are defined by the presence of a predominantly lymphocytic infiltration specifically targeting the islets of Langerhans. The infiltrating cells may be found in the islet periphery (peri-insulitis), often showing a characteristic tight focal aggregation at one pole of the islet that is in direct contact with the peripheral islet cells. The infiltrate may also be diffuse and present throughout the islet parenchyma (intra-insulitis). The lesion mainly affects islets containing insulin-positive cells and is always accompanied by the presence of (pseudo)atrophic islets devoid of beta cells. The fraction of infiltrated islets is generally low ( $<10 \%$ of islet profiles). The lesion should be established in a minimum of three islets, with a threshold level of $\geq 15 \mathrm{CD} 45^{+}$cells/islet before the diagnosis can be made. The pathology report should include the total number of islets analysed, the fraction of islets affected by insulitis, the fraction of (pseudo)atrophic islets, and a description of the spatial relationship of the infiltrate to the insulin-positive islet cells

Insulitis has, historically, been considered an inflammatory lesion of the islets of Langerhans, present in most children with recent-onset ( $<1$ year duration) type 1 diabetes as well as those subject to a rapid disease course $[1,2]$. Together with the presence of circulating autoantibodies directed against islet cell antigens, the predominantly lymphocytic infiltrate has been regarded as strong evidence for an (auto)immune aetiology of the disease [3]. However, despite its presumed central role in beta cell destruction, the lesion is not well studied in patient material. Only 150-200 cases of insulitis have been described over the past century and very few of these cases have been analysed in depth and with current methodologies. In a recent meta-analysis it was found that $73 \%$ of children with recentonset $(<1$ month duration) type 1 diabetes, between 0 and 14 years of age, showed insulitis compared with only $29 \%$ of 15-39 year-old recent-onset patients $[4,5]$. In contrast to the robust lesion observed in the NOD mouse model, insulitis in type 1 diabetic patients is often mild with respect to both the number of infiltrating cells [6] and the fraction of islets showing infiltration $(<10 \%)$ [4]. In addition, residual insulinpositive islets remain present in a majority of type 1 diabetic patients, even up to 50 years following diagnosis [7-9].

One of the primary, if not the most difficult, challenges to our understanding of the pathogenesis of type 1 diabetes is the comparison between histopathological studies of type 1 diabetic patients, a facet complicated by the lack of a consensus definition of insulitis. Indeed, not only are there multiple differences between the immunophenotyping markers that are used to identify insulitis, but also and especially, multiple different thresholds are used to distinguish between insulitis and background inflammatory infiltrates. For these reasons, the workshop participants considered it essential to agree on a consensus definition for this lesion and to identify quantitative and qualitative variables that characterise insulitis in type 1 diabetic patients. As part of this effort, it was decided that the definition should use variables that can be employed in a routine clinical histopathological setting to permit widespread application.

There was general agreement among participants that the majority of infiltrating cells in recent-onset type 1 diabetes would be of a lymphocytic nature and, in most cases, would have a predominantly $\mathrm{CD}^{+} \mathrm{CD} 8^{+}$phenotype [6,9] (Fig. 1). However, in view of the reportedly high B lymphocyte $\left(\mathrm{CD} 20^{+}\right)$content of inflamed islets in the more advanced stages of insulitis [6], it was agreed that the diagnosis of insulitis might be best based on immunohistochemical positivity for leucocyte common antigen $\left(\mathrm{CD} 45^{+}\right)$.

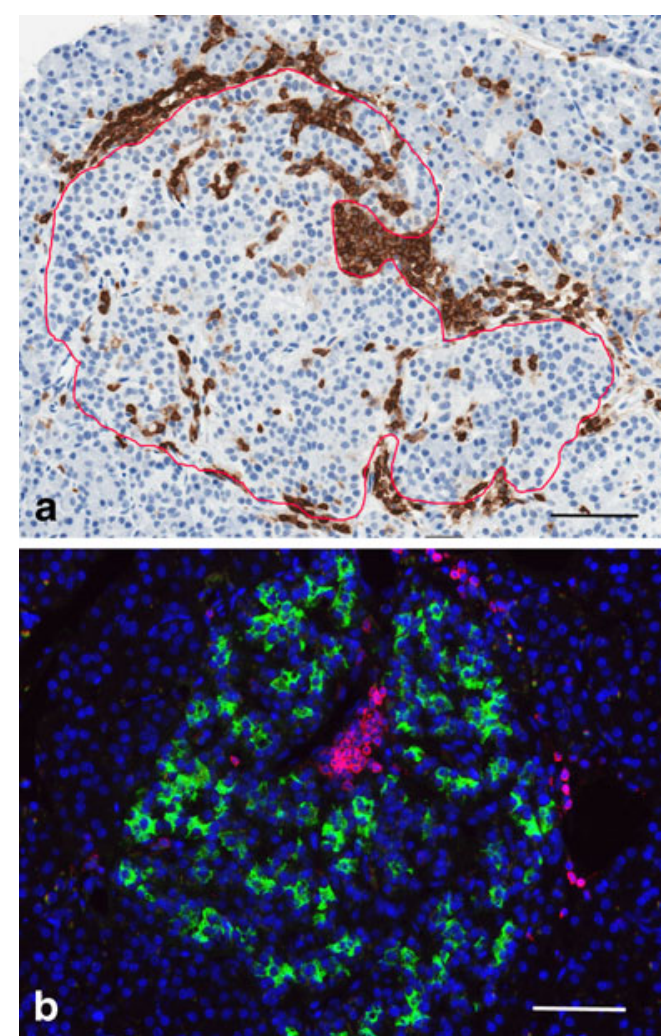

Fig. 1 Immunohistochemistry for leucocyte common antigen CD45 showing insulitis in human islets of Langerhans. A threshold of 15 $\mathrm{CD} 45^{+}$cells is proposed to define insulitis in individual islets. (a) Islet in the pancreatic body region of a 12-year-old boy with type 1 diabetes of 1 year's duration (case nPOD 6052), showing 249 CD $45^{+}$nucleated cells (brown) surrounding and infiltrating the islet (islet periphery outlined in red on the basis of a consecutive slide stained for islet hormones; single colour peroxidase staining). (b) Islet in the pancreatic tail region of a 66-year-old woman with type 1 diabetes of 20 years' duration (case BCBB 3450), showing 49 CD45 ${ }^{+}$nucleated cells (red) surrounding and infiltrating the islet (insulin staining in green; two colour immunofluorescence staining). Scale bars, $50 \mu \mathrm{m}$ 
As discussed above, it was also recognised that different studies dealing with histopathological changes in the type 1 diabetic pancreas have used different thresholds to define insulitis. These thresholds range from two to $15 \mathrm{CD}^{+}$or $\mathrm{CD} 45^{+}$cells adjacent to or infiltrating the islet $[6,9-14]$. However, recent observations in a cohort of 363 non-diabetic donor pancreases indicate that the level of background infiltration in the pancreatic parenchyma is highly variable and dependent on the clinical conditions surrounding organ retrieval, with the highest levels of infiltration observed in patients with a prolonged duration of life support [15]. Therefore, it was generally agreed that the threshold level should be substantially higher than the highest levels found in published controls; a level of $15 \mathrm{CD}^{+} 5^{+}$cells (approximately twice the highest number of $\mathrm{CD} 45^{+}$cells found in a single islet in a cohort of 62 control donor pancreases [14]) was accepted as a suitable threshold (Fig. 1), with the view that multiple islets should show this level of infiltration before a diagnosis of insulitis can be made for the patient under study. In this context, 'multiple' was defined as three or more with a standard islet size. While this standard islet size was not discussed at length in the workshop, it was pointed out in subsequent discussions between the authors of this letter that the standard islet diameter, in the context of human islet transplantation, is $150 \mu \mathrm{m}$. Furthermore, endocrine cell numbers may be used to distinguish islets from cell clusters [16].

There was general consensus that recent-onset and chronic type 1 diabetic patients almost always present with a variable fraction of (pseudo)atrophic islets devoid of beta cells [2, 17]. This lesion is therefore a hallmark of type 1 diabetes and should be present when a diagnosis of insulitis is made. Such (pseudo)atrophic islets may be found close to the inflamed islets or within any of the other tissue blocks examined. Indeed, they often constitute a significant part of the islet population in patients with a clinical diagnosis of type 1 diabetes [2].

Although most of the published literature stresses that insulitis is almost always found in islets in which residual beta cells are present $[2,17]$, it was pointed out at the workshop that these published studies are predominantly based on autopsy material and that recent efforts utilising material from type 1 diabetic organ donors indicate that the lesion may be more frequent in (pseudo)atrophic islets than previously recognised $[9,10]$. The consensus definition therefore states that the lesion 'mainly' affects islets containing beta cells. With this background, we therefore propose the consensus definition of insulitis detailed in the text box.

Acknowledgements The authors acknowledge the contribution of R. Gill (Department of Surgery and Immunology, University of Colorado, Denver, CO, USA) to the discussions underpinning the need for the definition, and thank the JDRF and the organisers of the nPOD symposium for their support.

Funding This statement was made possible through funding to nPOD by the JDRF (MAA).
Duality of interest The authors declare that there is no duality of interest associated with this manuscript.

Contribution statement All authors are responsible for the conception and design of the manuscript, drafting the article and revising it critically for important intellectual content. All authors approved the version to be published.

\section{References}

1. Gepts W (1965) Pathologic anatomy of the pancreas in juvenile diabetes mellitus. Diabetes 14:619-633

2. Foulis AK, Liddle CN, Farquharson MA, Richmond JA, Weir RS (1986) The histopathology of the pancreas in type 1 (insulin-dependent) diabetes mellitus: a 25 -year review of deaths in patients under 20 years of age in the United Kingdom. Diabetologia 29:267-274

3. Eisenbarth GS (1986) Type I diabetes mellitus. A chronic autoimmune disease. New Eng J Med 314:1360-1368

4. In't Veld P (2011) Insulitis in human type 1 diabetes: the quest for an elusive lesion. Islets 3:131-138

5. Pipeleers D, Ling Z (1992) Pancreatic beta cells in insulin-dependent diabetes. Diab Metab Rev 8:209-227

6. Willcox A, Richardson SJ, Bone AJ, Foulis AK, Morgan NG (2008) Analysis of islet inflammation in human type 1 diabetes. Clin Exp Immunol 155:173-181

7. Löhr M, Klöppel G (1987) Residual insulin positivity and pancreatic atrophy in relation to duration of chronic type 1 (insulin-dependent) diabetes mellitus and microangiopathy. Diabetologia 30:757-762

8. Keenan HA, Sun JK, Levine J et al (2010) Residual insulin production and pancreatic beta cell turnover after 50 years of diabetes: Joslin Medalist study. Diabetes 59:2846-2853

9. Gianani R, Campbell-Thompson M, Sarkar SA et al (2010) Dimorphic histopathology of long-standing childhood-onset diabetes. Diabetologia 53:690-698

10. Coppieters KT, Dotta DF, Amirian N et al (2012) Demonstration of islet-autoreactive CD8 T cells in insulitic lesions from diabetes patients. J Exp Med 209:51-60

11. Itoh N, Hanafusa T, Miyazaki A et al (1993) Mononuclear cell infiltration and its relation to the expression of major histocompatibility complex antigens and adhesion molecules in pancreas biopsy specimens from newly diagnosed insulin-dependent diabetes mellitus patients. J Clin Invest 92:2313-2322

12. Butler AE, Galasso R, Meier JJ, Basu R, Rizza RA, Butler PC (2007) Modestly increased beta cell apoptosis but no increased beta cell replication in recent-onset type 1 diabetic patients who died of ketoacidosis. Diabetologia 50:2323-2331

13. Campbell-Thompson M, Wasserfall C, Kaddis J et al (2012) Network for pancreatic organ donors with diabetes (nPOD): developing a tissue biobank for type 1 diabetes. Diabetes Metab Res Rev 28: 608-617

14. In't Veld P, Lievens D, de Grijse J et al (2007) Screening for insulitis in adult autoantibody-positive organ donors. Diabetes 56:2400-2404

15. In’t Veld PA, de Munck N, van Belle K et al (2010) Beta cell replication is increased in donor organs from young patients after prolonged life support. Diabetes 59:1702-1708

16. Campbell-Thompson M, Dixon LR, Wasserfall C et al (2009) Pancreatic adenocarcinoma patients with localised chronic severe pancreatitis show an increased number of single beta cells, without alterations in fractional insulin area. Diabetologia 52:262-270

17. Gepts W, de Mey J (1978) Islet cell survival determined by morphology: an immunocytochemical study of the islets of Langerhans in juvenile diabetes mellitus. Diabetes 27(Suppl 1):251-261 